\title{
The Kinetics and Mechanism of Atmospheric Corrosion Occurring on Tin and Iron-Tin Intermetallic Coated Steels
}

\section{Cathodic Delamination}

\author{
N. Wint, ${ }^{a, z}$ S. Geary, ${ }^{a}$ H. N. McMurray, ${ }^{a, *}$ G. Williams, ${ }^{a}$ and A. C. A. de Vooys ${ }^{b}$ \\ ${ }^{a}$ Materials Research Centre, College of Engineering, Swansea University, Bay Campus, Crymlyn Burrow, \\ Swansea SA1 8EN, United Kingdom \\ ${ }^{b}$ Tata Steel Research and Development, 1970 CA IJmuiden, The Netherlands
}

\begin{abstract}
This paper describes a systematic study into the initiation and propagation of cathodic delamination on pure iron, pure tin and industrially important tin and iron-tin intermetallic $\left(\mathrm{FeSn}\right.$ and $\left.\mathrm{FeSn}_{2}\right)$ coatings for packaging steels, as a function of coating weight. Cathodic disbondment rates for an organic lacquer overcoat applied to the various metallic coatings are determined using an in-situ scanning Kelvin probe technique. Cathodic disbondment was not observed on pure tin and was found to propagate at reduced rates on the FeSn and $\mathrm{FeSn}_{2}$ intermetallic coatings, relative to pure iron. An explanation of these findings is given in terms of electrocatalytic activity of various metallic surfaces for the cathodic oxygen reduction reaction. It is shown that the relative susceptibility of $\mathrm{Fe}$, $\mathrm{Sn}$, $\mathrm{FeSn}$ and $\mathrm{FeSn}_{2}$ to cathodic disbondment increases with decreasing cathodic overpotential and is independent of metallic coating weight.

(C) The Author(s) 2015. Published by ECS. This is an open access article distributed under the terms of the Creative Commons Attribution 4.0 License (CC BY, http://creativecommons.org/licenses/by/4.0/), which permits unrestricted reuse of the work in any medium, provided the original work is properly cited. [DOI: 10.1149/2.0681514jes] All rights reserved.
\end{abstract}

Manuscript submitted September 2, 2015; revised manuscript received October 5, 2015. Published October 20, 2015. This was Paper 796 presented at the Cancun, Mexico, Meeting of the Society, October 5-9, 2014.

Tin is traditionally used for the corrosion protection of packaging steel. Conventional tinplate is typically produced by initially electrodepositing a porous layer of pure tin $\left(\sim 2.8\right.$ g.m $\left.\mathrm{m}^{-2}-11.2 \mathrm{~g} . \mathrm{m}^{-2}\right)$ onto the cathodic steel substrate, as shown in Figure 1a, and heating above the melting point of tin (reflowing). ${ }^{1-3}$ Reflowing causes the tin layer to become fully dense (bright tin) and also allows creation of partial or complete iron-tin intermetallic, typically $\mathrm{FeSn}_{2}$, as shown in Figure $1 b^{1-3}$.

Recently the increasing price of tin in the commodities market has resulted in a need to reduce the amount of tin used in tinplate materials (tin coating weight) whilst retaining adequate corrosion resistance. One approach to doing this has been to diffusion anneal the unflowed tin $\left(<1 \mathrm{~g} . \mathrm{m}^{-2}\right)$ in a reducing atmosphere at temperatures above $500^{\circ} \mathrm{C}^{4,5}$ in such a way that almost all (preferably $\left.90-98 \%\right)^{6}$ of the free tin is converted to an iron-tin $(\mathrm{FeSn})$ intermetallic as shown in Figure 1c. It has previously been found that heating to these temperatures leads to increased tin diffusion to the substrate and formation of a continuous FeSn layer which is more uniform and dense than the conventional $\mathrm{FeSn}_{2}$ layer. ${ }^{4}$

The principal purpose of tin in tinplate packaging materials is to provide corrosion resistance. Furthermore, in modern packaging, corrosion resistance is enhanced by using tinplate in conjuction with an organic (laquer or laminate) overcoat. Consequently mechanisms of corrosion driven coating delamination are of particular concern. The aim of the current paper is to present a detailed study of the role of free tin and iron-tin intermetallic layers in resisting atmopheric corrosion, specifically cathodic disbondment, as it affects lacquer coated packaging material.

During cathodic delamination the separation of the organic coating from the metal substrate is linked to the cathodic reduction of oxygen. Within the localized corrosion cell anodic metal dissolution located in the vicinity of the defect is coupled to the cathodic delamination front by a thin $(<5 \mu \mathrm{m})$ gel like electrolyte which ingresses beneath the coating. ${ }^{7-9}$ Cathodic disbondment has previously been observed on pure iron, ${ }^{8-10}$ however there is little literature regarding the atmospheric corrosion of pure tin.

The importance of the cathodic oxygen reduction reaction (ORR) during the disbondment of organic coatings from metallic surfaces has been demonstrated elsewhere. ${ }^{11,12}$ It is suggested that the delamination of the polymer film from the metal substrate is attributed to the ORR

\footnotetext{
*Electrochemical Society Active Member.
}

${ }^{z}$ E-mail: 483404@swansea.ac.uk during which oxidizers such as $\mathrm{HO}_{2}$ and $\mathrm{H}_{2} \mathrm{O}_{2}$ and reactive species such as $\mathrm{OH}$ and $\mathrm{OH}^{-}$are created. ${ }^{11,12}$ There is very little published work that considers the ORR on tin. However it has been reported that oxygen reduction measurements could not be taken below $-0.4 \mathrm{~V}$ vs. SHE, and that very little hydrogen peroxide by the electrolytic reduction of oxygen is observed, on tin electrodes at near neutral pH. ${ }^{13}$

During the work described here a combination of scanning electron microscopy (SEM) and Brunauer-Emmett-Teller (BET) analysis was used to characterize tin and iron-tin intermetallic coated steel in terms of surface morphology and porosity. Samples were organically coated using a model polyvinyl butyral organic lacquer and their resistance to corrosion driven cathodic delamination was investigated by employing a 'Stratmann' type cell, $, 9,12$ and a $0.86 \mathrm{M}$ aqueous sodium chloride $(\mathrm{NaCl})$ electrolyte to reflect standard accelerated corrosion test conditions. The time dependent extent of cathodic disbondment was determined by repeated in situ scanning using a scanning Kelvin probe (SKP) apparatus. The capability of the SKP to visualize the spatial distribution of localized free corrosion potential variation with time has been demonstrated previously. ${ }^{8,14}$ The kinetics and mechanism of $\mathrm{O}_{2}$ reduction have been investigated with the aim of determining the extent to which increasing levels of tin influences cathodic overpotential, and subsequently clarify the role of tin in suppressing atmospheric types of corrosion such as cathodic delamination. In so doing we have used the rotating disk electrode (RDE) to obtain cathodic polarization characteristics for iron-tin intermetallic ( $\mathrm{FeSn}$ and $\mathrm{FeSn}_{2}$ ) and tin coatings in weakly alkaline $(\mathrm{pH} 9.3)$ aqueous sulfate electrolyte and compared these with pure iron and pure tin.

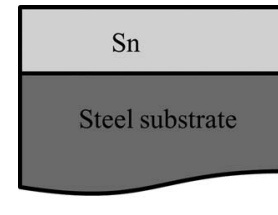

a.)

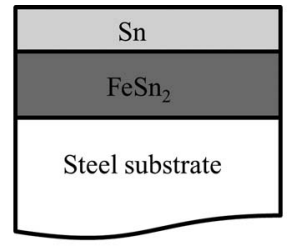

b.)

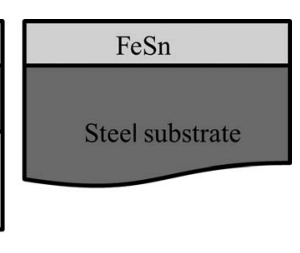

c.)
Figure 1. Schematic of the structure of a) steel coated with pure tin (unflowed tinplate) b) steel coated with $\mathrm{FeSn}_{2}$ intermetallic and surface free tin and c) steel coated with FeSn intermetallic. 


\section{Experimental}

Materials. - Iron foil of $0.15 \mathrm{~mm}$ thickness and $99.5 \%$ purity and tin foil of $0.25 \mathrm{~mm}$ thickness and $99.8 \%$ purity were obtained from Goodfellow Cambridge Ltd. Mild steel with three different types of tin based coating were obtained from Tata Steel Packaging. The first coating consisted of unflowed porous pure tin of coating weight $2.8 \mathrm{~g} . \mathrm{m}^{-2}$. The second coating consisted of reflowed FeSn present at coating weights 0.44 g.m $\mathrm{m}^{-2}$ and $0.88 \mathrm{~g} \cdot \mathrm{m}^{-2}$. The third coating was again reflowed and consisted of $\mathrm{FeSn}_{2}$. The $\mathrm{FeSn}_{2}$ coating was found to contain a small amount of surface free tin which was removed electrochemically by applying a controlled anodic current density in a $1 \mathrm{M}$ $\mathrm{HCl}$ electrolyte. ${ }^{15,16}$ The final $\mathrm{FeSn}_{2}$ coating weights were calculated as 0.37 g.m $\mathrm{m}^{-2}$ and $1.6 \mathrm{~g} . \mathrm{m}^{-2}$ using chronocoulometry.

Polyvinyl butyral (PVB) and all other chemicals were obtained from Aldrich Chemical Co. and of analytical grade purity. All samples were cleaned and degreased using ethanol and distilled water before experimentation.

Methods. - Images showing surface morphology and microstructure were obtained using both a Hitachi S-4800 and a JEOL JSM 35C scanning electron microscope (SEM).

The surface area and porosity data was obtained using BrunauerEmmett-Teller (BET) surface area analysis performed on a Tristar II 3020 (Micromeritics, USA) nitrogen adsorption-desorption apparatus. Each sample had been degassed for 21 hours at $80^{\circ} \mathrm{C}$ prior to nitrogen physisorption. A multiple point (eight) specific surface area type of analysis was carried out.

For RDE experiments, circular samples of $18 \mathrm{~mm}$ diameter were punched from the various metals. Prior to this, the pure iron and pure tin samples were prepared by abrading with silicon carbide paper. All electrochemical measurements were performed in aerated conditions at $20^{\circ} \mathrm{C}$ in $0.5 \mathrm{M}$ sodium sulfate containing $0.05 \mathrm{M}$ sodium tetraborate $\left(\mathrm{Na}_{2} \mathrm{~B}_{4} \mathrm{O}_{7} .10 \mathrm{H}_{2} \mathrm{O}\right)$ and $0.1 \mathrm{M}$ sodium hydroxide $(\mathrm{NaOH})$, which gave a buffered $\mathrm{pH}$ of 9.3. At this $\mathrm{pH}$ neither tin nor iron are active (i.e. their oxidation products are insoluble), this avoiding high dissolution rates. ${ }^{17,18}$ Samples were mounted in the PTFE holder of an Oxford Instruments RDE-2 rotating disk electrode system supplied by Sycopel Scientific. A Gamry mercury/mercurous sulfate reference electrode and a platinum gauze counter electrode were used. Polarization was carried out using a Solartron 1280 potentiostat. Prior to each experiment, the working electrode was held at a potential above the onset of visible hydrogen evolution for two minutes in order to reduce any air-formed oxide film. Quasi-steady state polarization curves were obtained using linear potential sweep rate of $3.3 \times 10^{-4}{\mathrm{~V} . \mathrm{s}^{-1}}^{-1}$ following a methodology described elsewhere. ${ }^{19}$ Due to the length of experiments, repeats were only conducted for one rotation speed on each material.

Cyclic voltammograms were conducted in deaerated conditions at a temperature of $20^{\circ} \mathrm{C}$ at a scan rate of $50 \mathrm{mV} \cdot \mathrm{s}^{-1}$. Samples were cathodically reduced at $-1.9 \mathrm{~V}$ vs SHE for five minutes prior to the scan to free the surface from oxide.

For cathodic delamination experiments all samples were solvent coated with $15 \%$ w/w ethanolic solution of polyvinyl butyral (PVB), molecular weight 70,000-100,000, lacquer using insulating tape height guides to give an air-dried thickness of $30 \mu \mathrm{m}$. Although PVB does not fully represent industrial coating systems it was used in the current work as it allows a measurable degree of delamination over a short time-scale. It is therefore considered to be a suitable alternative when the principal aim is the comparison of materials with respect to their ability to resist corrosion driven coating disbondment of organic coatings. A 'Stratmann' type cell ${ }^{8,9,12}$ was employed. Coatings were partially peeled back to create a defect comprising $20 \times$ $15 \mathrm{~mm}$ area of bare metal. A residual lip of clear adhesive tape and overcoated PVB formed a convenient barrier between intact polymer coated metal surface and the electrolyte applied to the defect area. Non corrosive silicone rubber was applied to the remaining edges of the defect to form a reservoir sufficient to contain $2 \mathrm{~cm}^{3}$ volume of corrosive electrolyte. When conducting cathodic delamination exper-

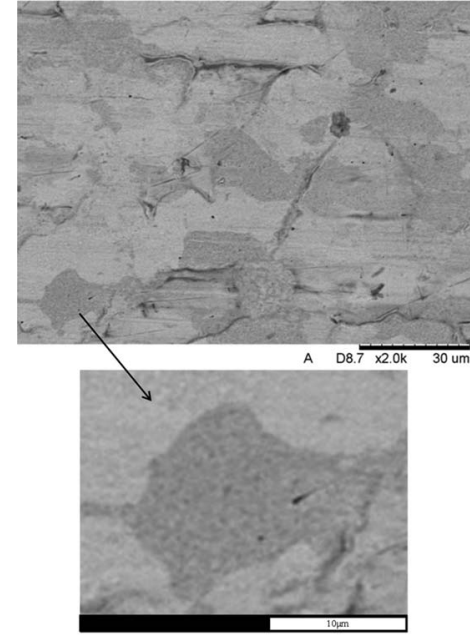

(a)

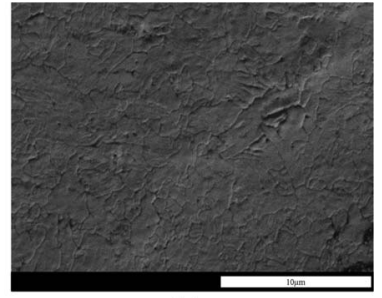

(b)

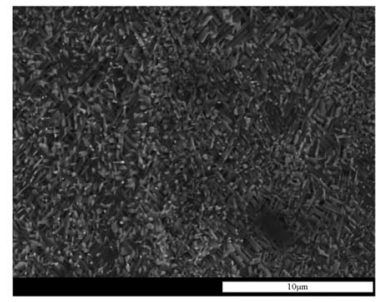

(c)
Figure 2. SEM images showing the microstructure of a) steel coated with pure tin (unflowed tinplate) b) FeSn and c) $\mathrm{FeSn}_{2}$. The white scale bar refers to $10 \mu \mathrm{m}$.

iments humidity was kept constant at $95 \%$ RH by use of electrolyte reservoirs containing $0.86 \mathrm{M}(5 \% \mathrm{w} / \mathrm{v})$ aqueous $\mathrm{NaCl}$ at $\mathrm{pH} 6.5$ in the chamber. Experiments took place at room temperature. An aliquot of electrolyte was applied to the defect to initiate the delamination. The SKP reference probe was moved over the surface along a $12 \mathrm{~mm}$ line up to the boundary of the defect. The SKP chamber was closed and scans taken at regular intervals after initiation. Scans were recorded as a numeric grid on the computer. Three repeat measurements were taken for each material.

\section{Results and Discussion}

Materials characterization. - The surface morphology of materials and porosity of the various metallic coatings were determined using a combination of SEM and $\mathrm{N}_{2}$ BET. The polished surfaces of pure iron and tin were featureless. Figure 2c shows that the $\mathrm{FeSn}_{2}$ surface is composed of a mass of interlocking needle like crystals of $\mathrm{FeSn}_{2}$ of length $\sim 1.5 \mu \mathrm{m}$ and width $\sim 0.5 \mu \mathrm{m}$, the orientation and coverage of which varies across the surface. ${ }^{20}$ Conversely Figure $2 \mathrm{a}$ and Figure $2 b$ show that both the unflowed tinplate and FeSn surfaces are relatively flat and composed of pancake like crystals in a tessellated arrangement. Sample coupons of size $4 \mathrm{~cm} \times 4 \mathrm{~cm}$, coated on one side only, were subject to $\mathrm{N}_{2}$ BET. In the case of the FeSn and unflowed tinplate, the measured BET surface areas were, within experimental error, identical with the geometrical surface area of the sample (16 $\mathrm{cm}^{2}$ ), this being determined assuming that the interface is truly flat. ${ }^{21}$ However, in the case of the $\mathrm{FeSn}_{2}$ coated sample the BET surface area, this being the true surface area taking into account nonidealities of the interface (roughness, porosity etc.), was $790.1 \pm 221.0 \mathrm{~cm}^{2}$, or $\sim 50$ times greater than the geometrical area of the coated surface. This finding is consistent with the $\mathrm{FeSn}_{2}$ morphology shown in Figure $2 \mathrm{c}$ and suggests that $\sim 98 \%$ of the sample area is internal. The $\mathrm{FeSn}_{2}$ coating weight was $1.6 \mathrm{~g} . \mathrm{m}^{-2}$, from which a specific surface area of $30.9 \mathrm{~m}^{2} \cdot \mathrm{g}^{-1}$ can be calculated.

Electrochemical characterization; Cathodic oxygen reduction reaction (ORR) characterization results.-In order to characterize the various surfaces in terms of their relative ability to electrocatalyze the ORR, a series of quasi potentiostatic anodic going polarization experiments were carried out using a rotating disk electrode (RDE). Figure 3 shows a series of anodic going polarization curves at different rotation speeds for a) pure iron b) pure tin c) unflowed tinplate, d) FeSn and e) $\mathrm{FeSn}_{2}$. Figure 3 shows that in all cases for disk rotation angular 


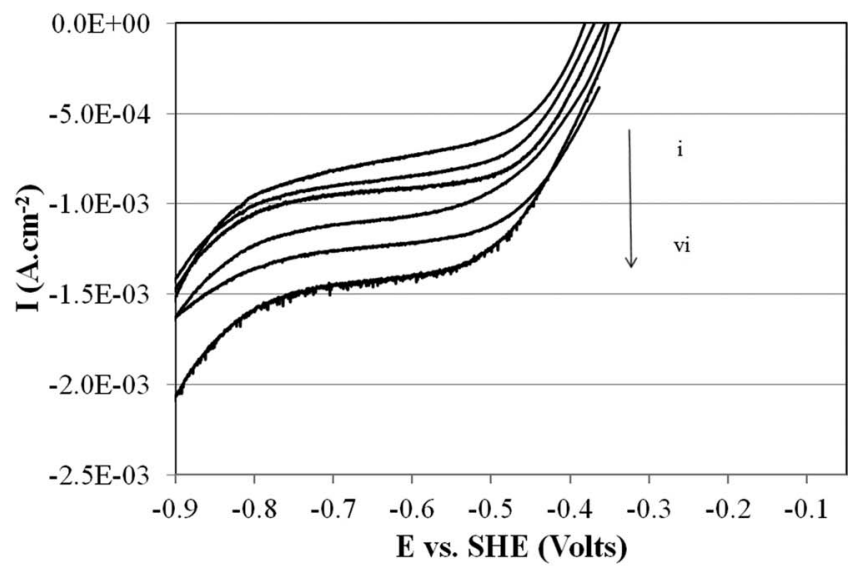

(a)

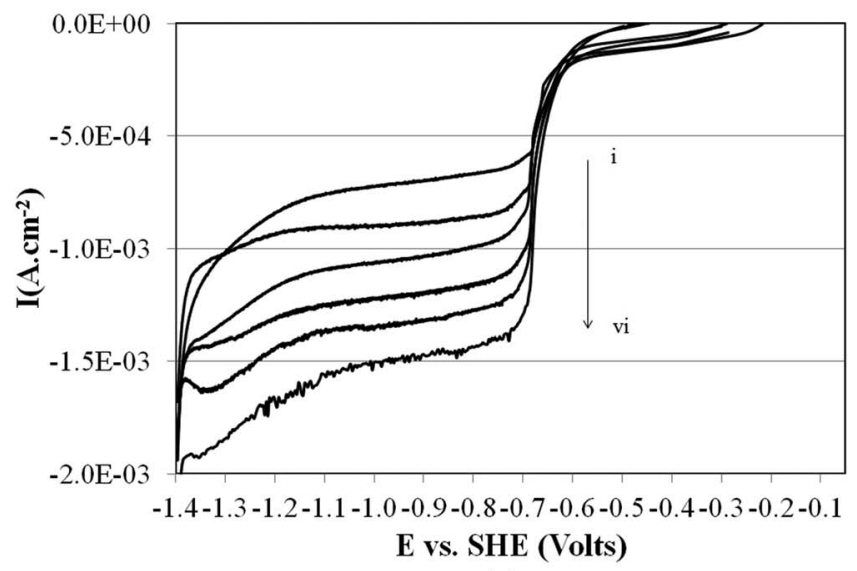

(c)

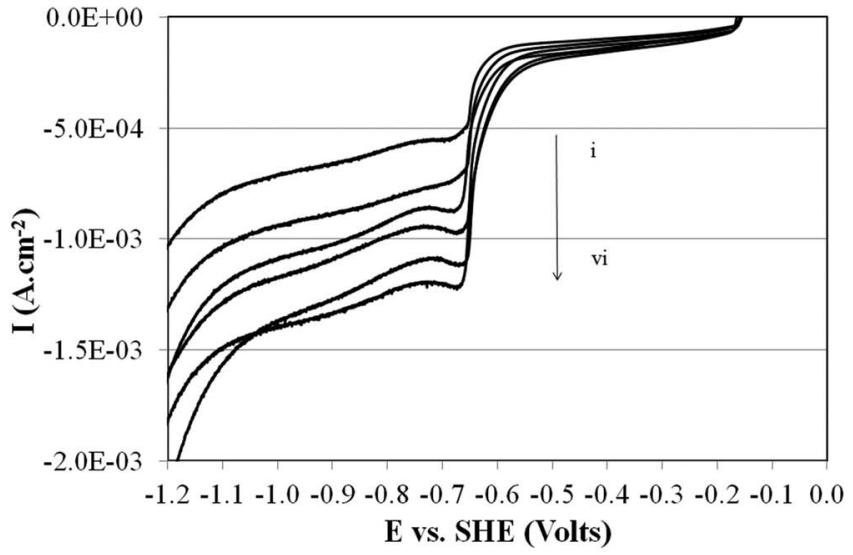

(b)

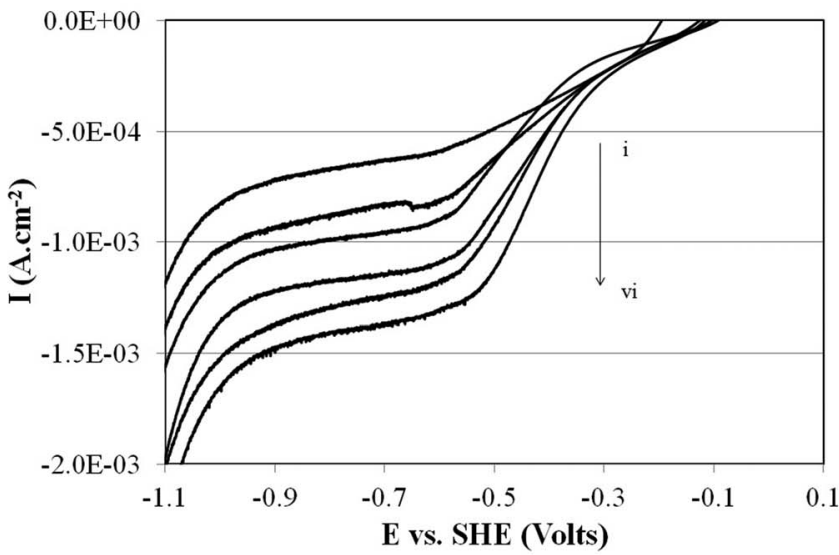

(d)

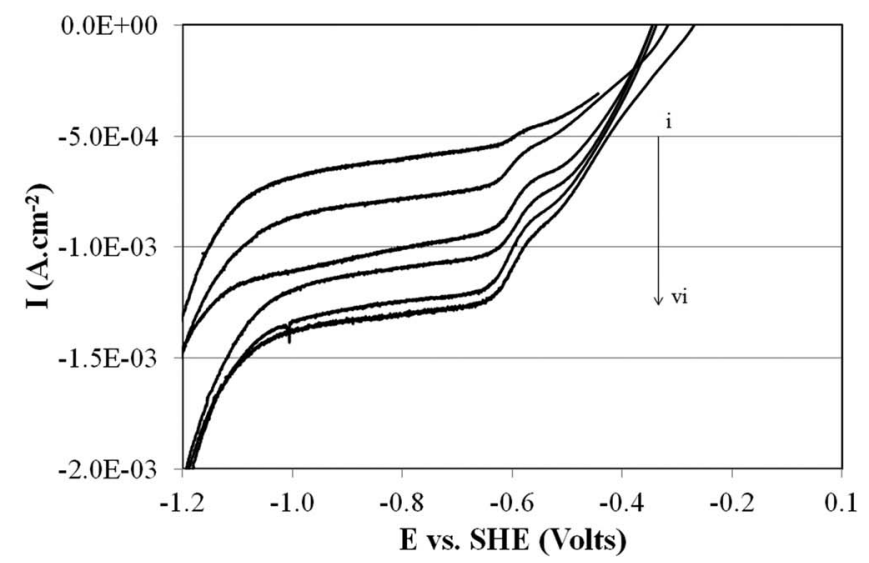

(e)

Figure 3. Disk current density as a function of potential in aerated $0.5 \mathrm{M} \mathrm{Na}_{2} \mathrm{SO}_{4}$ buffered to $\mathrm{pH} 9.3$ Potential sweep rate $3.3 \times 10^{-4} \mathrm{Vs}^{-1}$ for a) pure iron b) pure tin c) unflowed tinplate d) $\mathrm{FeSn}$ and e) $\mathrm{FeSn}_{2}$. Angular velocity key: i) 55, ii) 108, iii) 163, iv.) 217, v.) 271 and vi) 314 rad.s ${ }^{-1}$.

velocities $(w)$ between 55 and 314 rad.s ${ }^{-1}$ a well developed, rotation speed dependent, current plateau develops $<-0.7$ V vs. SHE. Only $\mathrm{FeSn}_{2}$ shows evidence of a second partially developed current plateau between $-0.5 \mathrm{~V}$ vs. SHE and $-0.45 \mathrm{~V}$ vs. SHE.

The rotation speed dependence of plateau current densities suggest diffusion control and therefore that the limiting current can be predicted by the Levich Equation 1

$$
\mathrm{i}_{\mathrm{L}}=0.62 \mathrm{nFD} \mathrm{D}^{2 / 3} \mathrm{v}^{-1 / 6} \mathrm{c} \omega^{1 / 2}
$$

where $i_{L}$ is the limiting current, $n$ is the number of electrons transferred per molecule of oxygen reduced, $F$ is the Faraday constant (96485 C. $\left.\mathrm{mol}^{-1}\right), c\left(\mathrm{~mol} . \mathrm{cm}^{-3}\right)$ the bulk concentration of dissolved oxygen,
$D$ is the oxygen diffusion coefficient $\left(\mathrm{cm}^{2} . \mathrm{s}^{-1}\right), v$ is the kinematic viscosity $\left(\mathrm{cm}^{2} \mathrm{~s}^{-1}\right)$ and $\omega$ is the angular velocity $\left.\left(\mathrm{rad} \mathrm{s}^{-1}\right)\right)^{22}$ Values were calculated using published data obtained at $20^{\circ} \mathrm{C} .\left(\mathrm{c}=2 \times 10^{-7}\right.$ mol.cm $\left.{ }^{-3}, \mathrm{D}=1.74 \times 10^{-5} \mathrm{~cm}^{2} \cdot \mathrm{s}^{-1}, \mathrm{v}=10^{-2} \mathrm{~cm}^{2} \cdot \mathrm{s}^{-1}\right) .23$

Figure 4 shows a series of Levich plots each of which has been constructed by plotting the relevant $i$ vs. $\omega^{1 / 2}$ values obtained from Figure 3. Also shown on Figure 4 are the theoretical Levich plots for the four electron (Equation 2) and $2 \mathrm{e}^{-}$(Equation 3) ORR. The theoretical slopes for these plots calculated using Equation 1 are 69.3 $\times 10^{-6} \mathrm{~A} . \mathrm{cm}^{-2} \cdot \mathrm{s}^{-1 / 2}$ and $34.7 \times 10^{-6} \mathrm{~A} \cdot \mathrm{cm}^{-2} \cdot \mathrm{s}^{-1 / 2}$ respectively.

In all cases the experimental $i$ values used in Figure 4 were obtained at the maximum cathodic overpotential that did not admit of 


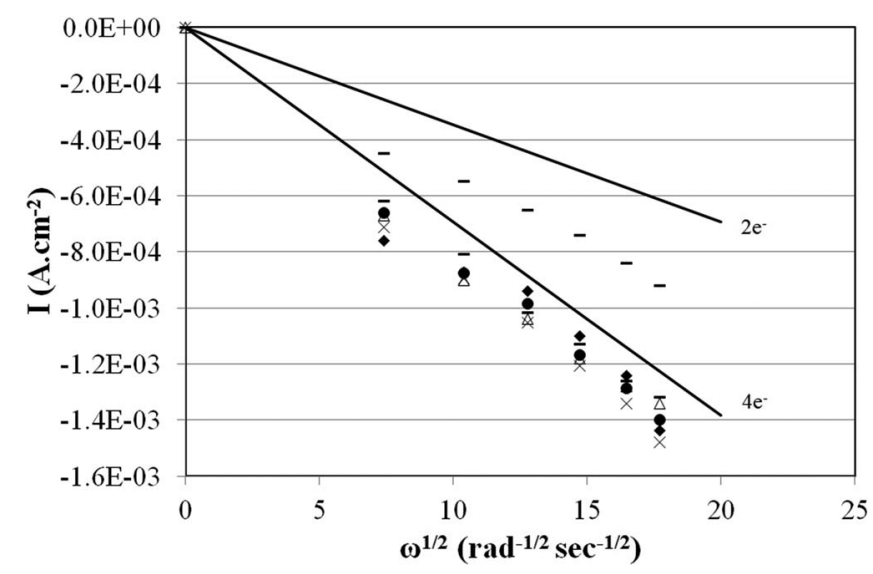

Figure 4. Levich slope obtained from anodic going potentiodynamic experiments for $\diamond$ pure iron, $\Delta$ pure tin, $\mathrm{X}$ unflowed tinplate, $\bullet \mathrm{FeSn}$ and $-\mathrm{FeSn}_{2}$ alongside theoretical values for both $4 \mathrm{e}^{-}$and $2 \mathrm{e}^{-}$oxygen reduction in aerated $0.5 \mathrm{M} \mathrm{Na}_{2} \mathrm{SO}_{4}$ buffered to $\mathrm{pH} 9.3$.

a significant current contribution from a competing electrochemical process, for example hydrogen evolution in the case of the $4 \mathrm{e}^{-}$ORR and the $4 \mathrm{e}^{-}$ORR in the case of the $2 \mathrm{e}^{-}$ORR. Experimental Levich slope values calculated by linear regression analysis of individual data sets, obtained from this graph, are given in Table I, together with corresponding values of $n e^{-}$. The slopes observed for all materials are offset from the theoretical slopes. This is due to the fact that the currents used are not purely diffusion limited currents, the offset value relating to $i_{k}$. Nevertheless, the plateaus observed in Figure 3 and are consistent with diffusion controlled $4 \mathrm{e}^{-}$oxygen reduction to hydroxyl ions $\left(\mathrm{OH}^{-}\right)$via Equation 2. As shown in Figure 3e and Table I in the case of $\mathrm{FeSn}_{2}$ the second plateau is consistent with $2 \mathrm{e}^{-}$oxygen reduction to $\mathrm{H}_{2} \mathrm{O}_{2}$ via Reaction $3 . \mathrm{H}_{2} \mathrm{O}_{2}$ may itself become oxidized via Reaction 4. Thus it is possible to observe $4 \mathrm{e}^{-}$and $2 \mathrm{e}^{-}$pathways alone and in combination.

$$
\begin{gathered}
\mathrm{O}_{2}+2 \mathrm{H}_{2} \mathrm{O}+4 \mathrm{e}^{-} \rightarrow 4 \mathrm{OH}^{-} \\
\mathrm{O}_{2}+\mathrm{H}_{2} \mathrm{O}+2 \mathrm{e}^{-} \rightarrow \mathrm{HO}_{2}^{-}+\mathrm{OH}^{-} \\
\mathrm{HO}_{2}^{-}+\mathrm{H}_{2} \mathrm{O}+2 \mathrm{e}^{-} \rightarrow 3 \mathrm{OH}^{-}
\end{gathered}
$$

Generally speaking $4 \mathrm{e}^{-}$ORR is observed on bare metal surfaces and $2 \mathrm{e}^{-}$ORR is observed on oxide covered surfaces. ${ }^{19}$ The formation and reduction of metal oxide at the metal solution interface is observable as a series of quasi-reversible peaks in the cyclic voltammogram associated with that interface. To confirm this, a series of cyclic voltammograms were obtained for the various surfaces in deoxygenated solution and are shown in Figure 5.

Figure 5a shows that three peaks appear in the anodic going wave of the cyclic voltammogram for pure iron centered on potentials of: (I) $-0.75 \mathrm{~V}$ vs. SHE, (II) $-0.35 \mathrm{~V}$ vs. SHE and (III) $0 \mathrm{~V}$ VS. SHE. The oxidation of metallic iron to $\mathrm{Fe}(\mathrm{OH})_{2}$ has been suggested on numerous

Table I. Levich slope values and corresponding values of $\mathbf{n}$ for all electrode materials.

\begin{tabular}{ccc} 
Electrode & Levich slope $\left(\times 10^{-6} \mathrm{~A} \mathrm{~cm}^{-2} \mathrm{~s}^{-1 / 2}\right)$ Value of $n \mathrm{e}^{-}$ \\
\hline Iron (Fe) & $62.2 \pm 4.4$ & $3.59 \pm 0.25$ \\
Tin (Sn) & $65.1 \pm 4.5$ & $3.76 \pm 0.26$ \\
Unflowed Tinplate & $73.4 \pm 5.2$ & $4.29 \pm 0.30$ \\
FeSn & $70.8 \pm 5.1$ & $4.09 \pm 0.29$ \\
$\mathrm{FeSn}_{2}(-0.8$ V vs. SHE) & $69.5 \pm 4.9$ & $4.02 \pm 0.28$ \\
$\mathrm{FeSn}_{2}(-0.5$ V vs. SHE) & $45.4 \pm 3.1$ & $2.62 \pm 0.18$
\end{tabular}

occasions. ${ }^{24-27}$ Peak I has previously been ascribed to the simultaneous dissolution of iron(II) and formation of a hydroxide layer. ${ }^{26}$ Peak II has previously been attributed to the subsequent formation of $\mathrm{Fe}_{3} \mathrm{O}_{4}$ and peak III to the formation of $\mathrm{Fe}_{2} \mathrm{O}_{3} .{ }^{27}$ The establishment of the diffusion limited current plateau for $4 \mathrm{e}^{-}$ORR in Figure $3 \mathrm{a}$ occurs at potentials $<-0.34 \mathrm{~V}$ vs. SHE and therefore at more negative potentials than oxide formation represented by peak II. This is consistent with the notion that the $4 \mathrm{e}^{-}$ORR, given by Equation 2 occurs on bare iron, or that partially covered with hydroxide, and the $2 \mathrm{e}^{-}$ORR, given by Equation 3, occurs on substantially oxide covered iron. ${ }^{28,29}$

Figure $5 \mathrm{~b}$ shows that for pure tin two peaks exist in the anodic going wave of the cyclic voltammogram centered on potentials of: (I) $-0.67 \mathrm{~V}$ vs. SHE and (II) $-0.58 \mathrm{~V}$ vs. SHE. These potential values are consistent with stepwise oxidation of metallic tin, firstly to Sn (II) (Peak I) and from this to Sn (IV) (Peak II). Peak I has therefore been attributed to the formation of either $\mathrm{SnO}$ or $\mathrm{Sn}(\mathrm{OH})_{2}$ ${ }^{17,18}$ Equations 5 and 6 show that these two species form at similar potentials. ${ }^{17,30}$ Peak II has been attributed to the oxidation of $\mathrm{SnO}$ or $\mathrm{Sn}(\mathrm{OH})_{2}$ to $\mathrm{Sn}(\mathrm{OH})_{4}$, which may subsequently become dehydrated to form $\mathrm{SnO}_{2} \cdot{ }^{18,31}$ According to Equation 7 dehydration of $\mathrm{Sn}(\mathrm{OH})_{4}$ involves a Gibbs energy change of $-38 \mathrm{~kJ} \mathrm{~mol}^{-1}$ and is therefore thermodynamically favorable. ${ }^{31,32}$ The establishment of the diffusion limited current plateau for $4 \mathrm{e}^{-}$ORR in Figure $3 \mathrm{~b}$ occurs at more negative potentials than oxide formation represented by peak I. This is consistent with the notion that the $4 \mathrm{e}^{-} \mathrm{ORR}$, given by Equation 2 occurs on bare tin and the $2 \mathrm{e}^{-}$ORR, given by Equation 3 occurs on oxide covered tin.

$$
\begin{aligned}
& \mathrm{Sn} / \mathrm{SnO} \quad \mathrm{E}=-0.104-0.0591 \mathrm{pH}=-0.654 \mathrm{~V} \text { vs SHE } \\
& \begin{aligned}
\mathrm{Sn} / \mathrm{Sn}(\mathrm{OH})_{2} \quad \mathrm{E}= & -0.091-0.0591 \mathrm{pH} \\
= & -0.641 \mathrm{~V} \text { vs. SHE } \quad(\mathrm{pH} 9.3) \\
\mathrm{Sn}(\mathrm{OH})_{4} & \rightarrow \mathrm{SnO}_{2}+2 \mathrm{H}_{2} \mathrm{O}
\end{aligned}
\end{aligned}
$$

The cyclic voltammogram for unflowed tinplate, Figure 5c, shows two peaks in the anodic going wave centered on potentials; I $-0.70 \mathrm{~V}$ vs. SHE and II $-0.65 \mathrm{~V}$ vs. SHE, which are entirely similar to those of peaks I and II for pure tin in Figure 5b. It is therefore reasonable to assume that peaks I and II in Figure 5c correspond to the formation of $\mathrm{Sn}$ (II) and $\mathrm{Sn}(\mathrm{IV})$ hydr(oxides) as in Figure 5b. It is however evident that the shapes and relative heights of peaks I and II in Figures 5b and $5 \mathrm{c}$ are dissimilar. These differences in peak shape may arise from differences in the purity, porosity and crystal size associated with the two substrates but we are not yet in a position to say what the definitive cause is.

Figure $5 \mathrm{~d}$ show two anodic peaks at $-0.61 \mathrm{~V}$ (I) vs. SHE and $-0.27 \mathrm{~V}$ (II) vs. SHE for the anodic going cycle of the voltammogram on $\mathrm{FeSn}$, the former value corresponding to the transition in behavior from diffusion controlled $4 \mathrm{e}^{-}$oxygen reduction seen on Figure $3 \mathrm{~d}$. Figure $5 \mathrm{~d}$ shows similarities with the voltammogram obtained in Figure 5a for pure iron, for which Peak I is proposed to represent $\mathrm{Fe}(\mathrm{OH})_{2}$ formation given by Equation 8 . However, the peaks observed in the anodic going wave on FeSn exhibit a positive shift in potential relative to those observed on pure iron. This is consistent with literature values for the Gibbs free energy for the formation of $\operatorname{FeSn}\left(\Delta \mathrm{G}_{\mathrm{f}}\right)$ shown in Table II. ${ }^{33}$ The $\Delta \mathrm{G}_{\mathrm{f}}$ formation of FeSn is consistent with a positive shift in equilibrium potential associated with the formation of $\mathrm{Fe}(\mathrm{OH})_{2}$ given by Equation 9, calculated using Equations 10 and 11 where $n$ corresponds to the number of electrons and $F$ the Faraday constant $\left(96487\right.$ C. $\left.\mathrm{mol}^{-1}\right)$. It is thus proposed that peaks observed in the anodic going wave of the cyclic voltammogram for FeSn seen in Figure 5d correspond predominantly to $\mathrm{Fe}(\mathrm{OH})_{2}$ formation and it is consequently postulated that the iron oxide governs the activity of the FeSn material. This proposal is supported by the positioning of reduction peaks in the cathodic going waves for pure iron and FeSn as seen in Figure 6. The potential at which specific oxides are formed is 


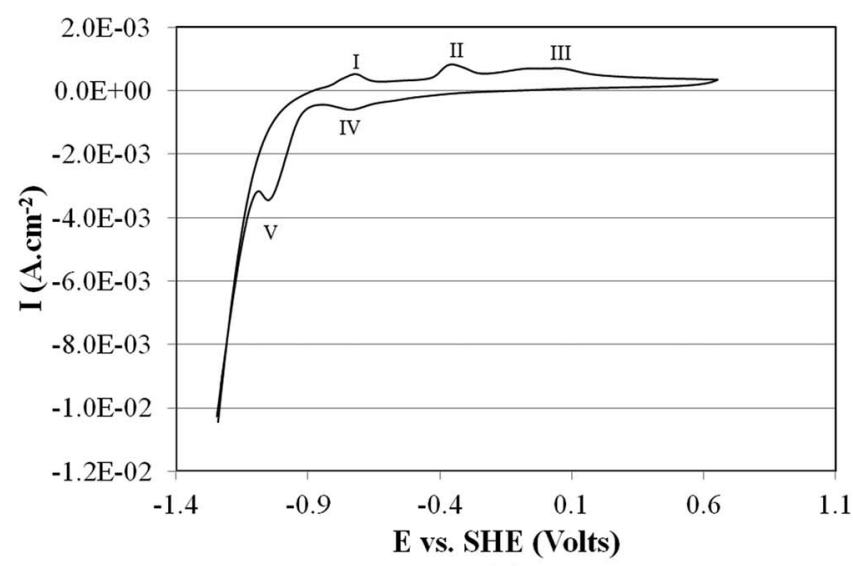

(a)

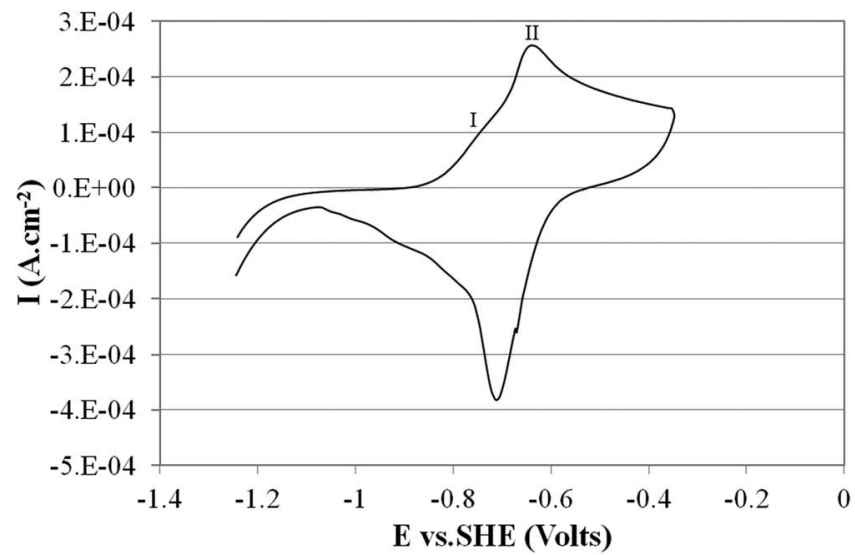

(c)

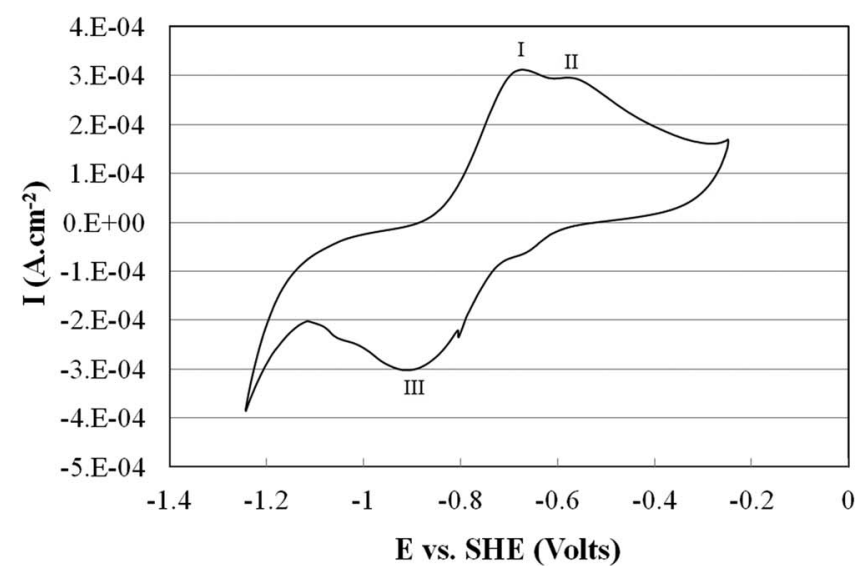

(b)

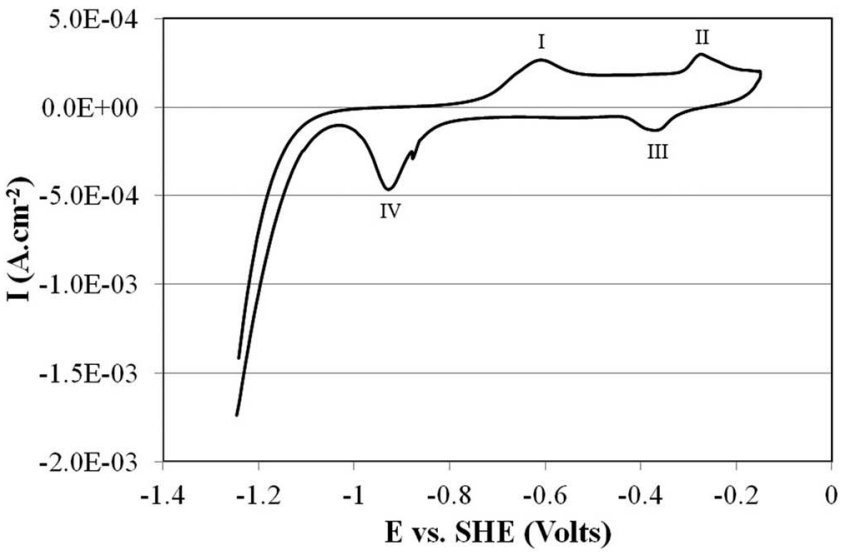

(d)

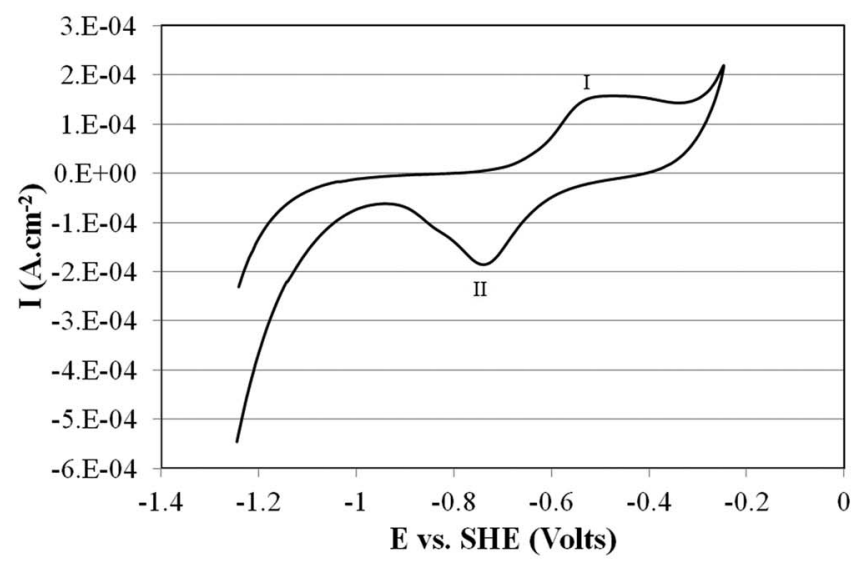

(e)

Figure 5. Cyclic voltammograms for a) pure iron b) pure tin c) unflowed tinplate d) $\mathrm{FeSn}$ and e) $\mathrm{FeSn}_{2}$ obtained in deaerated $0.5 \mathrm{M}$ sodium sulfate buffered to $\mathrm{pH}$ 9.3. Potential sweep rate $50 \mathrm{mV} \cdot \mathrm{s}^{-1}$.

dependent on the energetic stability of the intermetallic compound from which they are formed. In comparison the potential value at which a certain oxide is reduced to metallic metal is constant regardless of the intermetallic from which it was originally formed. The reduction peak (IV) seen in the cathodic going wave of the voltammogram for pure iron in Figure $5 \mathrm{a}$, centered on $-0.73 \mathrm{~V}$ vs. SHE, begins at the same value of the reduction peak (III) seen in the cathodic going wave of the voltammogram for FeSn in Figure 5d. In the case of pure iron, the peak, and thus reduction, occurs over a greater potential range due to the increased oxide formation during the anodic going sweep. The reduction peak (V) seen in Figure 5a for pure iron is observed at the same potentials as for peak (IV) in Figure $5 \mathrm{~d}$ for FeSn. It is consequently suggested that the same (iron) oxides are produced for both materials.

$$
\begin{gathered}
\mathrm{Fe}+2 \mathrm{H}_{2} \mathrm{O} \rightarrow \mathrm{Fe}(\mathrm{OH})_{2}+2 \mathrm{H}^{+}+2 \mathrm{e}^{-} \quad\left(\Delta \mathrm{G}_{1}\right) \\
\mathrm{FeSn}+2 \mathrm{H}_{2} \mathrm{O} \rightarrow \mathrm{Fe}(\mathrm{OH})_{2}+2 \mathrm{H}^{+}+2 \mathrm{e}^{-} \quad\left(\Delta \mathrm{G}_{2}\right) \\
\Delta \Delta G=\Delta \mathrm{G}_{1}-\Delta \mathrm{G}_{2}=\Delta \mathrm{G}_{\mathrm{fFeSn}}=-\mathrm{nF} \Delta \mathrm{E} \\
\Delta \mathrm{E}=-\Delta \Delta \mathrm{G} / \mathrm{nF}=-\Delta \mathrm{G}_{\mathrm{fFeSn}} / \mathrm{nF}
\end{gathered}
$$

Figure 5e shows one anodic peak at $-0.53 \mathrm{~V}$ (I) vs. SHE on $\mathrm{FeSn}_{2}$, the value corresponding to the transition in behavior from 
Table II. Comparison of calculated Gibbs energy values (J/Mole of atoms) of FeSn and $\mathrm{FeSn}_{2}$ with experimental data in literature alongside potentials. $^{33}$

Gibbs energy value $(\mathrm{J} / \mathrm{mole}) \mathrm{T}=293 \mathrm{~K}$

Potential (V vs. SHE) $\Delta G=-n F \Delta E$

$\begin{array}{cccc}\text { Calculated FeSn } & -17240 & n=2 & 0.089 \\ -23013+19.702 \mathrm{~T} & & n=4 & 0.045 \\ \text { Experimental FeSn } & -15184 & n=2 & 0.078 \\ -21142+20.334 \mathrm{~T} & & n=4 & 0.039 \\ \text { Experimental FeSn } & -20860 & n=2 & 0.108 \\ -27790+23.650 \mathrm{~T} & & n=4 & 0.054 \\ \text { Calculated } \mathrm{FeSn} & & n=2 & 0.099 \\ -27624+28.803 \mathrm{~T} & n=4 & 0.050 \\ \text { Experimental } \mathrm{FeSn} & n=2 & 0.102 \\ -27916+28.368 \mathrm{~T} & & n=4 & 0.051 \\ \text { Experimental } \mathrm{FeSn} & n=2 & 0.079 \\ -24140+30.520 \mathrm{~T} & & n=4 & 0.039\end{array}$

diffusion controlled $4 \mathrm{e}^{-}$oxygen reduction seen on Figure $3 \mathrm{e}$. The cyclic voltammogram shown in Figure 5 e for $\mathrm{FeSn}_{2}$ shows similarities with the voltammogram obtained in Figure $5 \mathrm{~b}$ for pure tin. However, the peak (I) observed at a potential of $-0.55 \mathrm{~V}$ vs. SHE in the anodic going wave on $\mathrm{FeSn}_{2}$ exhibits a positive shift in potential of $\sim 0.1$ $\mathrm{V}$ vs. SHE relative to those observed on pure tin by analogy of the proceeding argument regarding FeSn. This shift is consistent with literature values for the Gibbs free energy for the formation of $\mathrm{FeSn}_{2}$ $\left(\Delta \mathrm{G}_{\mathrm{f}}\right)$ shown in Table II. ${ }^{33}$ The values are consistent with the potential shift observed between the cyclic voltammogram for tin and $\mathrm{FeSn}_{2}$. It is thus proposed that the peak observed in the anodic going wave of the cyclic voltammogram for $\mathrm{FeSn}_{2}$ seen in Figure 5e corresponds to tin oxidation and it is consequently postulated that the tin oxide governs the activity of the $\mathrm{FeSn}_{2}$ material. The reduction peak (II) observed in the cathodic going wave of the voltammogram for $\mathrm{FeSn}_{2}$ in Figure $5 \mathrm{e}$ is centered on the same potential $(-0.75 \mathrm{~V}$ vs. SHE) at which the peak (III) observed in the cathodic going wave of the voltammogram for pure tin in Figure $5 \mathrm{~b}$ begins. In the case of pure tin the peak, and thus reduction, occurs over a greater potential range due to the increased oxide formation during the anodic going sweep. This is further demonstrated by Figure 7 .

The electrochemical parameter most likely to influence the susceptibility of a metallic surface to the corrosion driven delamination of an organic overcoat is arguably the ORR overpotential. For this reason an ORR overpotential value was obtained for all relevant surfaces. It

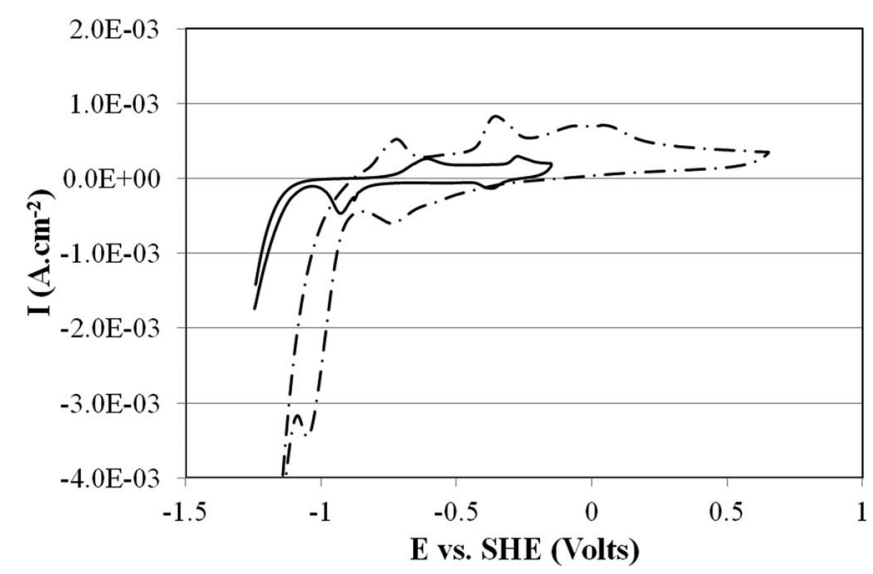

Figure 6. Cyclic voltammograms for FeSn compared to _..... pure iron obtained in deaerated $0.5 \mathrm{M}$ sodium sulfate buffered to $\mathrm{pH} 9.3$. Potential sweep rate $50 \mathrm{mV} \cdot \mathrm{s}^{-1}$. has been shown elsewhere that the ORR is first order with respect to $\mathrm{O}_{2}$ on iron. ${ }^{28}$ Under these circumstances, disk current density $(i)$ is related to the mass transport limiting current density $\left(i_{L}\right)$ by the Levich-Koutecky Equation 12.

$$
\frac{1}{i}=\frac{1}{i_{k}}+\frac{1}{i_{L}}
$$

where $i_{\mathrm{k}}$ is the kinetic current density. ${ }^{22,28}$ Assuming that $\mathrm{O}_{2}$ reduction on pure tin is also first order, $i_{\mathrm{k}}$ values may be calculated from $i$ using Equation 12 . An overpotential value was thus obtained from those regions of the relevant quasi-potentiostatic curves near the OCP where the surface was oxide covered and $2 \mathrm{e}^{-}$ORR was likely to predominate. In order to ensure that the overpotential value thus obtained was, to the greatest extent possible, a kinetic overpotential (i.e. with minimum diffusion contribution) correction was applied using Equation 12. The relevant $2 \mathrm{e}^{-} \mathrm{i}_{\mathrm{L}}$ values were estimated directly from the $\mathrm{FeSn}_{2}$ curve or by dividing the $4 \mathrm{e}^{-} \mathrm{i}_{\mathrm{L}}$ values by a factor of two for all other materials.

Measurements were taken from the anodic going curves measured at $\omega=163 \mathrm{rad} . \mathrm{s}^{-1}$, shown in Figure 8, for each material. This rotation speed was considered a compromise between maximizing $i_{L}$, and hence the useable range of $i_{k}$, without suffering the degradation introduced as a result of reduced signal to noise ratio observed at higher speeds.

Potentials $(E)$ were expressed as an overpotential $\eta_{O R}$ for the reduction of oxygen as calculated using Equations 13 and 14 and assuming

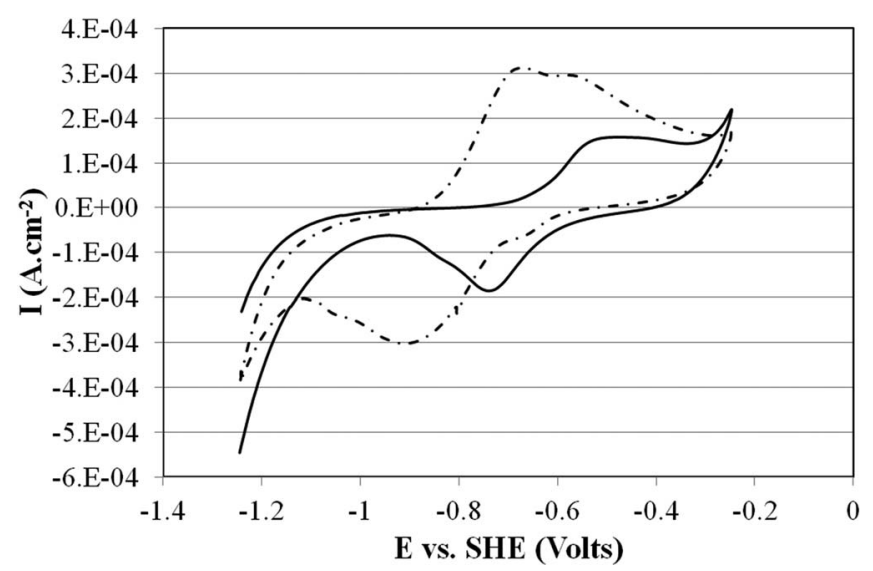

Figure 7. Cyclic voltammograms for $\mathrm{FeSn}_{2}$ compared to _._._._. pure tin obtained in deaerated $0.5 \mathrm{M}$ sodium sulfate buffered to $\mathrm{pH} 9.3$. Potential sweep rate $50 \mathrm{mV} \cdot \mathrm{s}^{-1}$. 


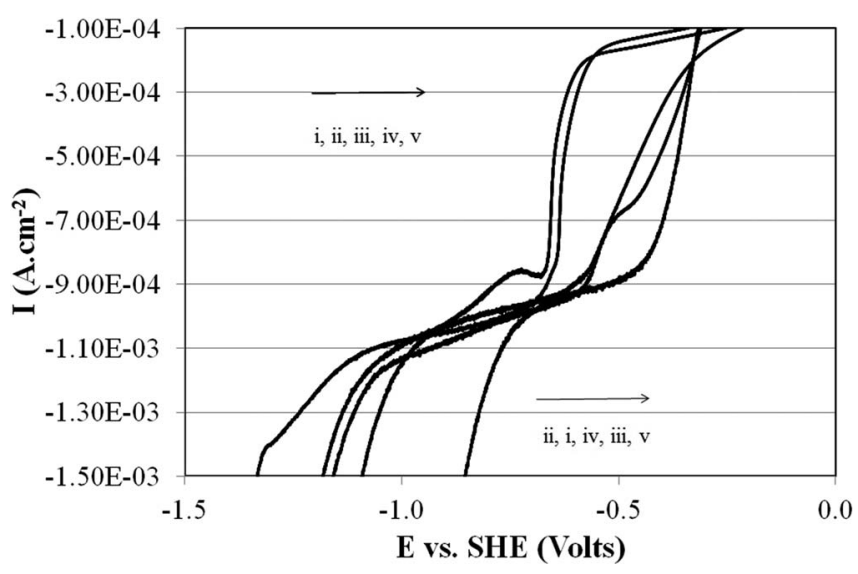

Figure 8. Anodic going polarization curves obtained in aerated $0.5 \mathrm{M}$ aqueous $\mathrm{Na}_{2} \mathrm{SO}_{4}$, borate buffered at $\mathrm{pH} 9.3$. Potential sweep rate $3.3 \times 10^{-4} \mathrm{~V}^{-}{ }^{-1}$. Material key i) pure tin, ii) unflowed tinplate, iii) $\mathrm{FeSn}$ iv) $\mathrm{FeSn}_{2}$, and v) pure iron. Angular velocity $163 \mathrm{rad} . \mathrm{s}^{-1}$.

the partial pressure of oxygen to be $0.2 \mathrm{~atm}$.

$$
\eta_{\mathrm{OR}}=\mathrm{E}-\mathrm{Ee}_{\mathrm{q}}
$$

$$
\mathrm{E}_{\mathrm{eq}}=1.228-0.0591 \mathrm{pH}+0.0147 \log p \mathrm{O}_{2}
$$

$$
2 \mathrm{H}_{2} \mathrm{O}=\mathrm{O}_{2}+4 \mathrm{H}^{+}+4 \mathrm{e}^{-}
$$

$$
\mathrm{Sn} \rightarrow \mathrm{Sn}^{2+}+2 \mathrm{e}^{-}
$$

The standard deviation on the mean potential value (at a given current) for three repeats experiments was calculated. The percentage error was applied to all data sets, this being illustrated by the error bars in Figure 9.

Figure 9 confirms that $\mathrm{FeSn}$ and $\mathrm{FeSn}_{2}$ coatings are significantly better electrocatalysts for $\mathrm{O}_{2}$ reduction than is pure tin or steel coated with unflowed tinplate. The value of $\eta_{\mathrm{OR}}$ is approximately $0.25 \mathrm{~V}$ greater on pure tin and unflowed tinplate than on iron. A higher $\eta_{\mathrm{OR}}$ values is obtained for $\mathrm{FeSn}$ than $\mathrm{FeSn}_{2}$, this being consistent with results obtained previously whereby the cathodic polarization of $\mathrm{FeSn}$ was found to be larger than that on $\mathrm{FeSn}_{2} \cdot{ }^{34}$ However, these results were obtained using acidic electrolytes and did not consider coating porosity and true surface area. In the present case the $\eta_{\mathrm{OR}}$ values

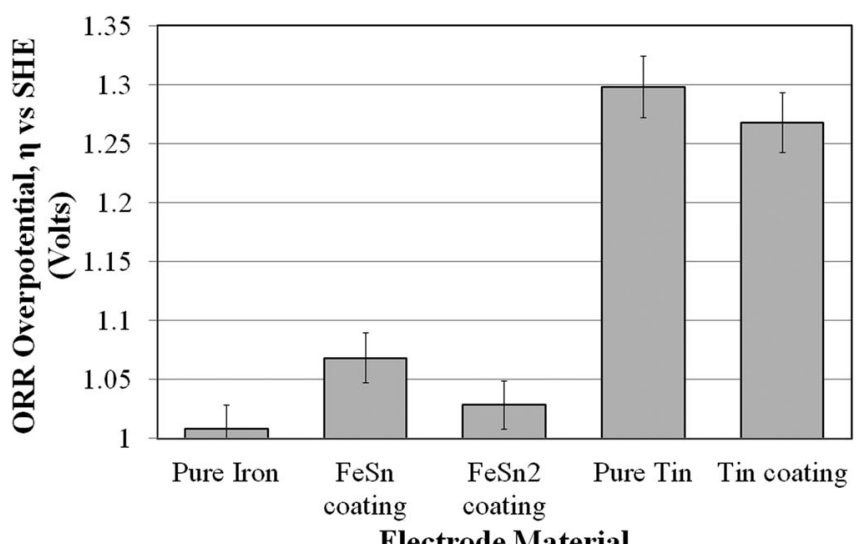

Figure 9. Overpotential for oxygen reduction acquired from anodic polarization curves obtained for pure iron, pure tin, unflowed tinplate, $\mathrm{FeSn}$ and $\mathrm{FeSn}$ coated steel tested in aerated $0.5 \mathrm{M} \mathrm{Na}_{2} \mathrm{SO}_{4}$ buffered to $\mathrm{pH} 9.3$ Potential sweep rate $3.3 \times 10^{-4} \mathrm{~V} . \mathrm{s}^{-1}$. Rotation rate $163{\mathrm{rad} . \mathrm{s}^{-1}}^{-1}$

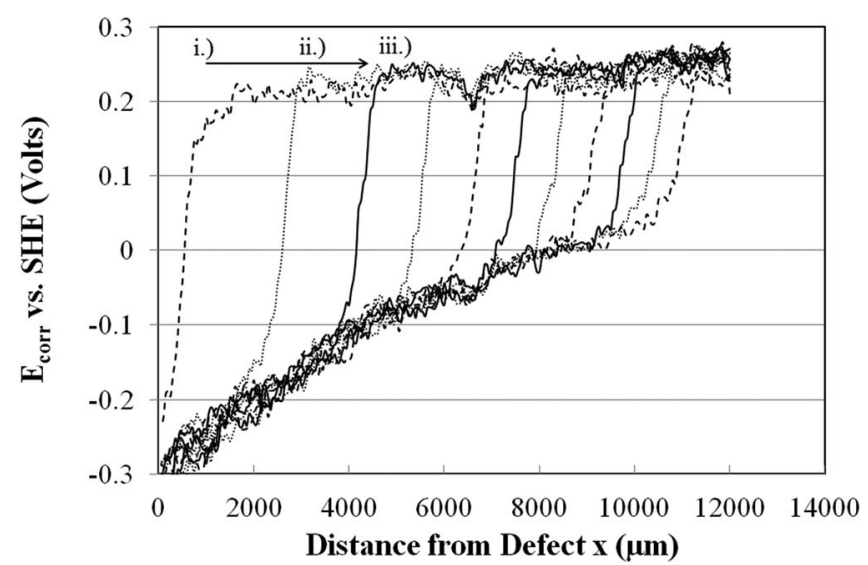

Figure 10. SKP derived $E_{\text {corr }}$ vs. distance $(x)$ profiles for pure iron overcoated with a $30 \mu \mathrm{m}$ PVB film, held in air at $95 \%$ R.H., where corrosion was initiated using $0.86 \mathrm{M} \mathrm{NaCl}$ (aq.) applied to a penetrative coating defect. Time key i) 60 mins ii) 120 mins iii) 180 mins and one hour intervals thereafter.

are stated for current density values calculated using the geometric surface area of the sample. It should therefore be considered that the increased true area of $\mathrm{FeSn}_{2}$, calculated using BET, would allow a greater area over which electron transfer may occur. This would increase the kinetic current contribution and thus reduce the $\eta_{\mathrm{OR}}$ value. Cathodic delamination results.-The kinetics of disbondment of the PVB lacquer from pure iron was determined in an initial experiment to establish baseline characteristics. After initiation the time dependent $E_{\text {corr }}(x)$ profiles (where $x$ is distance from the defect edge) became established and are shown in Figure 10. $E_{\text {corr }}$ values over the intact coating surface $\left(E_{\text {intact }}\right)$ were uniformly high and remained constant at ca. $0.2 \mathrm{~V}$ vs. SHE, this being similar to those reported previously. ${ }^{10}$ $E_{\text {corr }}$ values in the vicinity of the delamination front fall to ca. -0.3 vs. SHE, this being expected for anodically active iron (ca. $-0.44 \mathrm{~V}$ vs. SHE).$^{8,9,12,14}$ It has been shown that during coating delamination, a local cathode resulting from the oxygen reduction reaction (ORR) exists in the region of the delamination front resulting in loss of coating adhesion. Anodic iron dissolution is constrained to the vicinity of the coating defect. ${ }^{8}$ The anodic and cathodic reactions are linked by the ionic transport of current through the underfilm electrolyte. Throughout the duration of the experiment, the electrolyte ingresses farther under the coating. The linear gradient in potential between $E_{c o r r}$ at the delamination front and undelaminated region is the result of the ionic conductivity in the underfilm electrolyte. The point of maximum gradient in time dependent $E_{\text {corr }}(x)$ profiles has been identified as a semi-empirical means of locating the cathodic delamination front. ${ }^{8,10,35}$ As delamination time increases the linear gradient moves farther away from the defect. The rate of this progression decreases with time. This is indicative of the delamination rate being controlled by the migration of electrolyte cations (here $\mathrm{Na}^{+}$) from external (defect zone) electrolyte to the cathodic delamination front. Under these circumstances the distance $\left(x_{d e l}\right)$ over which delamination has occurred is related to the time since electrolyte contact $\left(t_{d e l}\right)$ by;

$$
x_{d e l}=k_{d}\left(t_{d e l}-t_{i}\right)^{1 / 2}
$$

where $k_{d}$ is the delamination rate constant and $t_{i}$ the initiation period. Figure 11 shows plots of $x_{d e l}$ vs. $\left(t_{d e l}-t_{i}\right)^{1 / 2}$ obtained from time dependent $E_{\text {corr }}$ profiles for iron. The curve is a good straight line consistent with migration control and thus parabolic kinetics. The $k_{d}$ value obtained from the gradient was $(550 \pm 79) \mu \mathrm{m} \cdot \mathrm{min}^{-1 / 2}$. The confidence limits (errors) shown correspond to \pm one unit of standard deviation on the mean. Error bars are omitted for the sake of clarity.

Cathodic driven coating delamination was not observed on unflowed tinplate over a time period of 96 hours, for three repeat measurements, this being made evident by the potential plateau shown in Figure 12. 


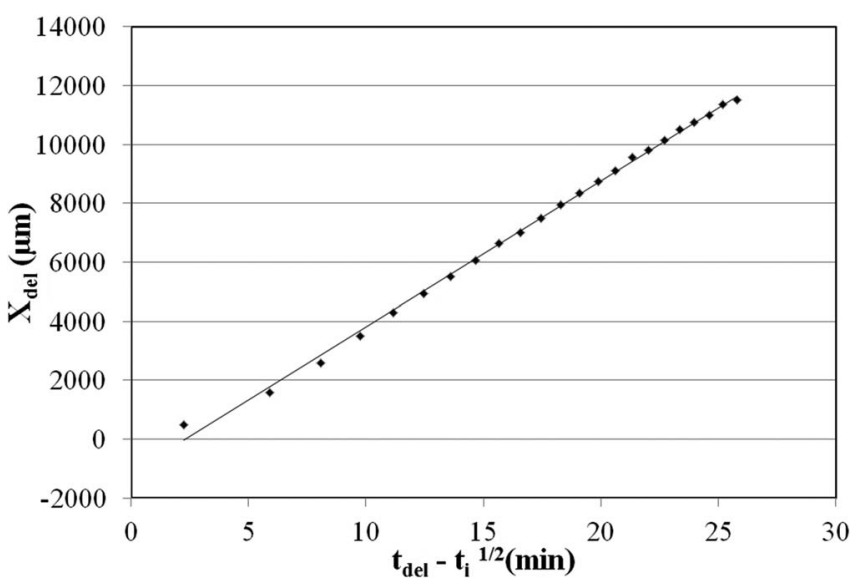

Figure 11. Plots of delamination distance $\left(x_{d e l}\right)$ vs. $t^{1 / 2}$ obtained for a pure iron sample overcoated with a $30 \mu \mathrm{m}$ PVB film where corrosion was initiated using a $0.86 \mathrm{M} \mathrm{NaCl}$ electrolyte.

Figure 13 shows that the potential in the intact region on 0.88 g.m $\mathrm{m}^{-2} \mathrm{FeSn}$ remains constant at ca. $0.3 \mathrm{~V}$ vs. SHE, this being $0.1 \mathrm{~V}$ higher than that on iron. Figure 14 shows plots of $x_{d e l}$ vs. $\left(t_{d e l}-t_{i}\right)^{1 / 2}$ obtained from time dependent $E_{c o r r}$ profiles. The curve is a good straight line consistent with migration control and thus parabolic kinetics. The $k_{d}$ value obtained from the gradient was $(537 \pm 77)$ $\mu \mathrm{m} \cdot \mathrm{min}^{-1 / 2}$. The delamination rate obtained is, within experimental error, identical to that observed on iron. This finding is supported by RDE data given in Figure 9 which shows the overpotential values for the cathodic oxygen reduction reaction for both pure iron and $\mathrm{FeSn}$ are similar.

The $k_{d}$ values obtained from Figure 15 for $0.88 \mathrm{~g} . \mathrm{m}^{-2}$ and 0.44 g.m $\mathrm{m}^{-2} \mathrm{FeSn}$ were $(537 \pm 77) \mu \mathrm{m} \cdot \mathrm{min}^{-1 / 2}$ and $(400 \pm 57) \mu \mathrm{m} \cdot \mathrm{min}^{-1 / 2}$ respectively, and are therefore similar, within experimental error. This suggests that anodic dissolution of the intermetallic coating is not rate determining during cathodic disbondment.

Figure 16 shows that the potential measured for the intact region on $\mathrm{FeSn}_{2}$ was constant at ca. $0.3 \mathrm{~V}$ vs. SHE, this being similar to the value obtained on FeSn. The $k_{d}$ value obtained from the gradient of the line in Figure 17 was $(121.6 \pm 17) \mu \mathrm{m} . \mathrm{min}^{-1 / 2}$ this being substantially lower than for those obtained on both pure iron and FeSn.

In all cases the rate of cathodic delamination is limited by the migrational mass transport of cations in the underfilm electrolyte and therefore disbondment rate is not related to catalytic activity for the ORR. ${ }^{9,12}$ It has been shown elsewhere that the rate of oxygen

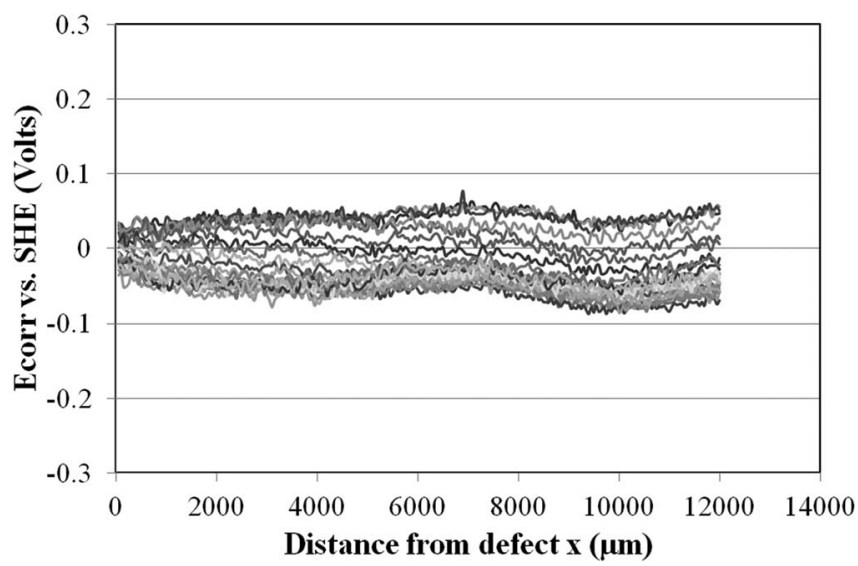

Figure 12. SKP derived $E_{\text {corr }}$ vs. distance $(x)$ profiles for unflowed tinplate overcoated with a $30 \mu \mathrm{m}$ PVB film, held in air at $95 \%$ R.H., where corrosion was initiated using $0.86 \mathrm{M} \mathrm{NaCl}$ (aq.) applied to a penetrative coating defect.

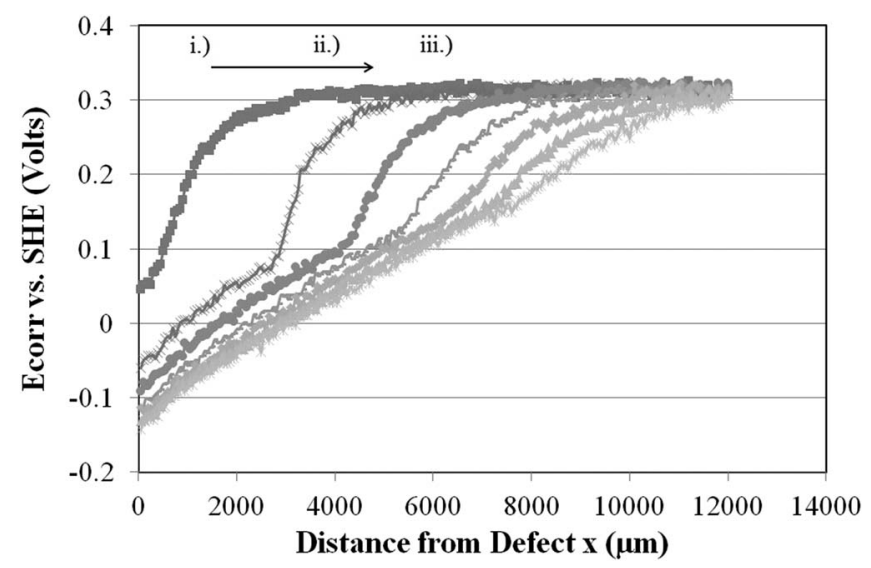

Figure 13. SKP derived $E_{\text {corr }}$ vs. distance ( $x$ ) profiles for a 0.88 g.m ${ }^{-2} \mathrm{FeSn}$ coated steel overcoated with a $30 \mu \mathrm{m}$ PVB film, held in air at 95\% R.H., where corrosion was initiated using $0.86 \mathrm{M} \mathrm{NaCl}$ (aq.) applied to a penetrative coating defect. Time key i) 270 mins ii) 330 mins iii) 390 mins and one hour intervals thereafter.

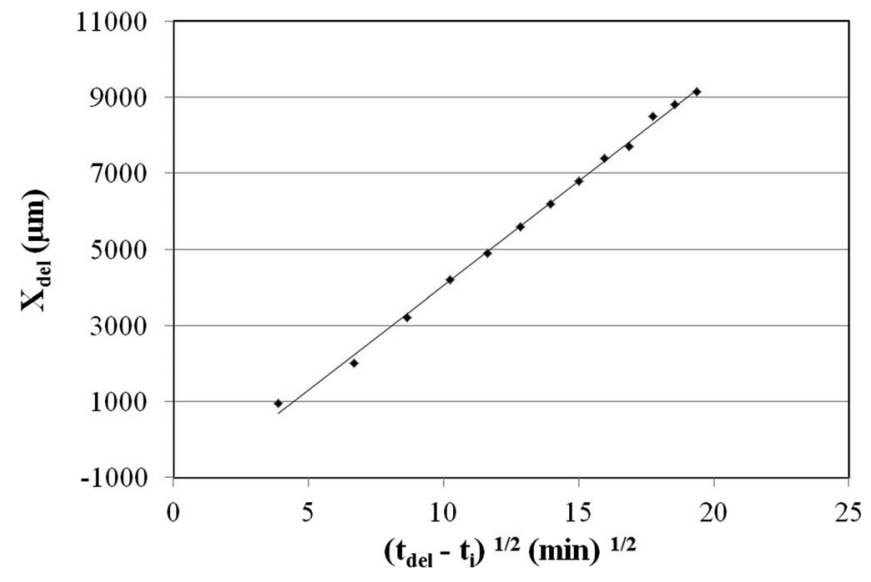

Figure 14. Plots of delamination distance $\left(x_{\text {del }}\right)$ vs. $t^{1 / 2}$ obtained for a 0.88 g.m $\mathrm{m}^{-2} \mathrm{FeSn}$ coated steel sample overcoated with a $30 \mu \mathrm{m}$ PVB film where corrosion was initiated using a $0.86 \mathrm{M} \mathrm{NaCl}$ electrolyte.

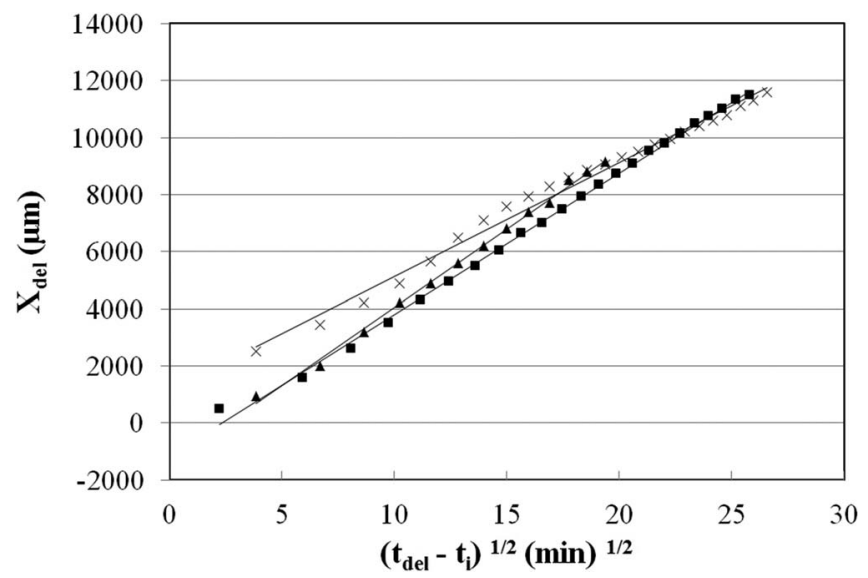

Figure 15. Plots of delamination distance $\left(x_{d e l}\right)$ vs. $t^{1 / 2}$ obtained for $\boldsymbol{\Delta}$ pure iron, x 0.44 g.m ${ }^{-2}$ FeSn coated steel and 0.88 g.m ${ }^{-2}$ FeSn coated steel overcoated with a $30 \mu \mathrm{m}$ PVB film where corrosion was initiated using a $0.86 \mathrm{M} \mathrm{NaCl}$ electrolyte. 


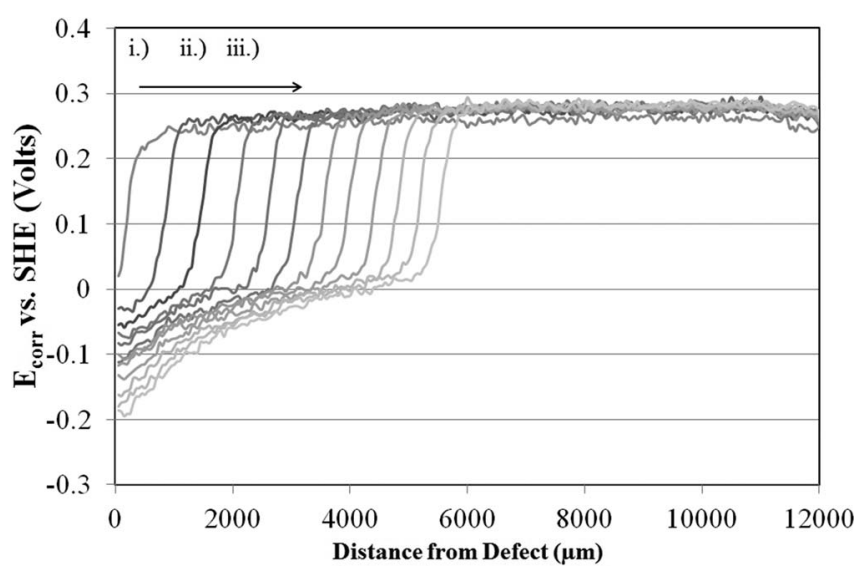

Figure 16. SKP derived $E_{\text {corr }}$ vs. distance $(x)$ profiles for a 1.6 g.m ${ }^{-2} \mathrm{FeSn}_{2}$ coated steel overcoated with a $30 \mu \mathrm{m}$ PVB film, held in air at 95\% R.H., where corrosion was initiated using $0.86 \mathrm{M} \mathrm{NaCl}$ (aq.) applied to a penetrative coating defect. Time key i) 1320 mins ii) 1560 mins iii) 1800 mins and 240 minute intervals thereafter.

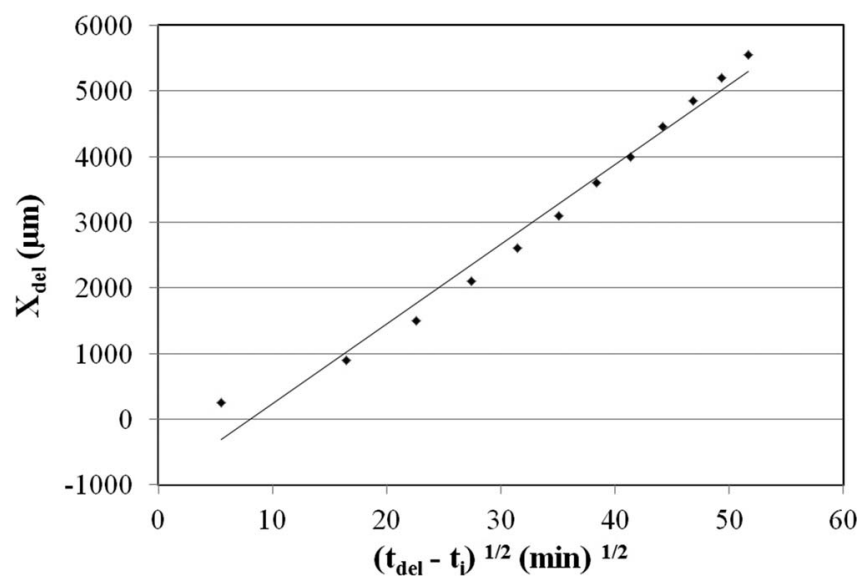

Figure 17. Plots of delamination distance $\left(x_{\text {del }}\right)$ vs. $t^{1 / 2}$ obtained for a 1.6 g. $\mathrm{m}^{-2} \mathrm{FeSn}_{2}$ coated steel sample overcoated with a $30 \mu \mathrm{m}$ PVB film where corrosion was initiated using a $0.86 \mathrm{M} \mathrm{NaCl}$ electrolyte.

reduction need only be small for the chemical destruction of the interface. ${ }^{36}$ Furthermore on surfaces where the ORR is extremely inhibited, the potentials of freshly prepared samples are very low and increase only slowly with exposure to air $^{37}$ Consequently the relatively high potentials of $\sim 300 \mathrm{mV}$ vs. SHE observed in Figure 13 and Figure 16 on intact $\mathrm{FeSn}$ and $\mathrm{FeSn}_{2}$ respectively, in comparison to $\sim 0$ $\mathrm{mV}$ vs. SHE observed in the case of intact tin (Figure 12), indicate that a substantial rate for the ORR is possible in the case of both materials. It is thus suggested that the rate of cathodic delamination is substantially reduced in the case of $\mathrm{FeSn}_{2}$, when compared to both pure iron and $\mathrm{FeSn}$, due to higher true surface area $(50 \times$ geometric surface area). The increased area results in the unit area delamination, and therefore the true delaminated distance, being greater than the unit linear delamination distance, as travelled by the SKP. Other possible explanations are that an increased amount of oxide blocks the ORR at the $\mathrm{FeSn}_{2}$-coating interface ${ }^{38}$ or that the cation migration rate is slower due to a more torturous migration path.

\section{Conclusions}

A systematic study has been completed to show that;

- Cathodic delamination was not observed to initiate on steel coated with pure tin.
- Cathodic delamination on FeSn was found to occur at a similar rate to that observed on pure iron. The rate of disbondment remained constant with variation in coating weight.

- Cathodic delamination was observed on $\mathrm{FeSn}_{2}$ at a significantly reduced rate to that measured on both pure iron and $\mathrm{FeSn}$.

Materials characterization was carried out using SEM and $\mathrm{N}_{2}$ BET to show that;

- The $\mathrm{FeSn}_{2}$ coating exhibits a true surface area $\sim 50$ times greater than its geometrical area.

- Unflowed tinplate and FeSn were relatively flat and featureless and the measured BET surface areas were, within experimental error, identical with geometric surface area.

An electrochemical study has been completed to show that;

- The relative electrocatalytic activity for the cathodic oxygen reduction reaction (ORR) was found to decrease in the order $\mathrm{Fe}<\mathrm{FeSn}<\mathrm{FeSn}_{2} \ll \mathrm{Sn}$ when calculated using true (as opposed to geometric) surface area,

- FeSn had a higher overpotential value for the ORR than $\mathrm{FeSn}_{2}$ when calculated using geometric surface area.

It is proposed that;

- cathodic disbondment is not observed on unflowed tinplate due to the high overpotential for the ORR associated with tin.

- anodic dissolution is not necessary during cathodic delamination, this notion being supported by the fact that similar cathodic delamination rates were obtained for varying intermetallic coating weight

- the significantly reduced rate of cathodic coating disbondment on $\mathrm{FeSn}_{2}$, when compared to $\mathrm{FeSn}$ and pure iron, is due to its increased true surface area which results in an larger true delamination distance, when compared to the distance travelled by the SKP, and thus the distance over which electrode potential values associated with coating disbondment were recorded.

\section{Acknowledgments}

The authors thank the European Social Fund (ESF) through the Welsh Government for the financial support of the Steel Training Research and Innovation Partnership (STRIP). In addition, the support from TATA Steel is gratefully acknowledged. Cecile Charbonneau is kindly thanked for providing BET data.

\section{References}

1. X. Huang, F. Langi, Y. Ma, Y. Chen, Z. Zhang, and J. Zhang, Transactions of Nonferrous Metals Society of China, 24, 1978 (2014).

2. E. Morgan, Tinplate and Modern Can making Technology, Pergamon Press Ltd, Oxford (1985).

3. I. Suzuki, Corrosion Resistant Coatings Technology, Marcel Dekker, New York (1989).

4. M. Fujinami, K. Yoshida, Y. Ujihira, and M. Terasaka, Journal of Materials Science, 20, 4099 (1985).

5. H. Kuroda, I. Onoda, T. Inui, and Y. Kondo, Characteristics of Lightly Tin Coated Steel Sheets, p. 124, The Proceedings of the Second International Tinplate Conference, London (1980).

6. I. Portegies Zwart and J. H. O. J. Wijenberg, Tata Steel Ijmuiden, Process for producing an iron-tin layer on a packaging steel substrate, Pat. WO 2012/045791, 12 April, 2012.

7. G. Williams and H. N. McMurray, in Shreir's Corrosion, B. R. A. Cottis, M. Graham, R. Lindsay, S. Lyon, T. J. A. Richardson, D. J. D. Scantlebury, and H. Stott, Editors, p. 988, Elsevier Science (2009).

8. A. Leng, H. Streckel, and M. Stratmann, Corrosion Science, 41, 547 (1999).

9. A. Leng, H. Streckel, and M. Stratmann, Corrosion Science, 41, 579 (1999).

10. R. J. Holness, G. Williams, and D. A. Worsley, Journal of the Electrochemical Society, 152, B73 (1995).

11. H. Leidheiser, NACE, 387, 374 (1982).

12. M. Stratmann, R. Feser, and A. Leng, Electrochimica Acta, 39, 1207 (1994).

13. P. Delahay, Journal of the Electrochemical Society, 97(6), 205 (1950). 
14. M. Stratmann, H. Streckel, and R. Feser, Corrosion Science, 32, 467 (1991).

15. American Society for Testing and Materials, Standard Test Methods for Determination of Tin Coating Weights for Electrolytic Tinplate, A 630-98, p. 4 (1998).

16. A. Ninčević Grassino, Z. Grabarić, A. Pezzani, G. Fasanaro, and A. Lo Voi, Food and Chemical Toxicology, 47(7), 1556 (2009).

17. M. Pourbaix, Atlas of Electrochemical Equilibria in Aqueous Solutions, Pergamon Press (1966).

18. S. D. Kapusta and N. Hackerman, Electrochimica Acta, 25(12), 1625 (1980).

19. H. Dafydd, D. A. Worsley, and H. N. McMurray, Corrosion Science, 47(12), 3006 (2005)

20. H. E. Biber and W. T. Harter, Journal of the Electrochemical Society, 113, 828 (1966).

21. A. J. Bard, G. Inzelt, and F. Scholz, Electrochemical Dictionary, Springer Science and Business Media (2012).

22. V. G. Levich, Physicochemical Hydrodynamics, Prentice Hall Inc, Englewood Cliffs, NJ (1962).

23. A. Bonnel, F. Dabosi, C. Deslouis, M. Dupart, M. Keddam, and B. Tribollet, Journal of the Electrochemical Society, 130(4), 753 (1983).

24. D. Geana, A. A. El Miligy, and W. J. Lorenz, Journal of Applied Electrochemistry, 4, 337 (1974).

25. O. Khaselev and J. M. Sykes, Electrochimica Acta, 42, 2333 (1997).

26. V. Jovancicevic, R. C. Kainthla, Z. Tang, B. Yang, and J. O'M. Bockris, Langmuir, 3, 388 (1987).
27. D. D. Macdonald and D. Owen, Journal of the Electorchemical Society, 120, 317 (1973).

28. V. Jovancicevic and J. O'M. Bockris, Journal of the Electrochemical Society, 133(9), 1797 (1986)

29. S. Zečević, D. M. Dražić, and S. Gojković, Journal of Electroanalytical Chemistry and Interfacial Electrochemistry, 265, 179 (1989).

30. M. Pugh, L. M. Warner, and D. W. Gabe, Corrosion Science, 7, 807 (1967).

31. M. Šeruga, M. Metikoš-Huković, T. Valla, M. Milun, H. Hoffschultz, and K. Wandelt, Journal of Electroanalytical Chemistry, 407, 83 (1996).

32. A. M. Shams El Din and F. M. Abd El Wahab, Electrochimica Acta, 9, 883 (1964).

33. K. C. Hari Kumar, P. Wollants, and L. Delaey, Calphad, 20(2), 139 (1996).

34. H. Kuroda, H. Kagechika, T. Inui, and Y. Kondo, Characteristics of FeSn-Alloyed Tinplate, p. 201, The Proceedings of the Third International Tinplate Conference, London (1984).

35. G. Williams and H. N. McMurray, Journal of the Electrochemical Society, 148, B377 (2001).

36. A. Leng, H. Streckel, and M. Stratmann, Corrosion Science, 41, 599 (1999).

37. R. Hausbrand, M. Stratmann, and M. Rohwerder, Journal of the Electrochemical Society, 155, C369 (2008).

38. G. Williams, R. J. Holness, D. A. Worsley, and H. N. McMurray, Electrochemistry Communications, 6, 549 (2004). 